\title{
MALE AND FEMALE SOCIAL MEDIA INFLUENCERS: THE IMPACT OF GENDER ON EMERGING ADULTS
}

\author{
Komathi Lokithasan ${ }^{1}$ \\ Faculty Arts and Social Science, \\ Universiti Tunku Abdul Rahman (UTAR), Malaysia. \\ (Email: komathil@utar.edu.my) \\ Salomi Simon ${ }^{2}$ \\ Faculty Arts and Social Science, \\ Universiti Tunku Abdul Rahman (UTAR), Malaysia. \\ (Email: salomi@utar.edu.my) \\ Nur Zahrawaani Binti Jasmin ${ }^{3}$ \\ Faculty Arts and Social Science, \\ Universiti Tunku Abdul Rahman (UTAR, Malaysia. \\ (Email: zahrawaani@utar.edu.my) \\ Nur Ajeerah Binti Othman ${ }^{4}$ \\ Faculty of Social Science \& Humanities, \\ Universiti kebangsaan Malaysia (UKM), Malaysia. \\ (Email: P97333@siswa.ukm.edu.my)
}

Received date: 03-06-2019

Revised date: 13-06-2019

Accepted date: $10-09-2019$

Published date: 11-09-2019

To cite this document: Lokithasan, K., Simon, S., Jasmin, N. Z., \& Othman, N. A. (2019). Male and Female Social Media Influencers: The Impact of Gender on Emerging Adults. International Journal of Modern Trends in Social Sciences, 2(9), 21-30.

DOI: $10.35631 / \mathrm{IJMTSS} .29003$

\begin{abstract}
Social media influencers are people who have established a reputation for themselves on social media. Nowadays, a social media influencer has played the important role of a marketing tool for organizations. Organizations use the power of social media influencers to influence and persuade consumers through social media. It is because social media influencers have a huge number of followers in their social media, thus, social media influencer could promote to and reach a large number of consumers in a short time. The result is more effective than celebrity endorsement for small-and-medium-sized enterprises (SME). This research is to study the perceptions of emerging adults on the difference between male and female social media influencers' style of promotion. Qualitative method is used by conducting a focus group and content analysis to compare the impact of male and female social media influencers towards emerging adults. Findings showed that female respondents are influenced by influencers who promote beauty products while male respondents are drawn to technology and gaming products. The most important factors mentioned by the respondents in the impact of the social media influencers' posts are the entertainment factor and followed by informativeness.
\end{abstract}

Keywords: Social Media Influencers, Emerging Adults, Gender Communication Theory 


\section{Introduction}

The trend of using social media have transformed over the years (Hussain, 2012). The early history of social media returns to the 1980s and beginner driven exchange gatherings, for examples, USENT groups or Bulletin Board Systems (BBS) where social media users accumulated to share their perspectives, experiences and interest. Over the years, social media sites have transformed into one of the most important channels for users to connect and communicate with others (Riga, 2016). Until now, social media has become one of the important channels for organization in marketing communications (Gashi, 2017). Organizations currently having a harder time to connecting with large number of consumers in a same moment, thus, social media influencers have been used as a problem solution for impact the purchase decisions of consumers. Social media influencers are first investigating in the promotional field and helps in expand social media coverage in online (Lim et al., 2017).

An influencer is characterized as a person who has the ability to influence other's purchase decision as a result of their power, information or relationship with their audience. Being an "influencer" implies a specific way of life, societal position and now a profession. Some of the influencers bring home the bacon out of their internet-based life abilities, some view it as a side employment and energy. They prepare to be proficient, invest hours setting up the best substance and connecting with their audiences. Their companions and other social media users impact them the most (rather than conventional media which has little impact). They expand items they see inside the social media world in which they live (IndaHash, 2017).

Gender norms impact the preference for a specific utilization of social media. Male gender utilized social media for systems administration, making new companions, and searching out potential dates and playing online games; while female gender utilized it for relationship support and posting public message (Efosa, Nubi \& Ogechi 2017). However, most social media settings include a blend of the two genders. This has suggestions for how teenagers self-display (Herring \& Kapidzic, 2015). IndaHash conducted with 2285 active global influencers taking part stated that female social media influencer occupy $68 \% .47 \%$ of female influencers (vs $36 \%$ male) post content on their personal site 1-3 times a day. $45 \%$ (vs $31 \%$ male) purchased something they found in social media in the most recent week. $62 \%$ (vs $48 \%$ male) stated that others social media users are most supposition shaping for them.

\section{Statement of Problem}

Social media influencer marketing is a new trend of marketing and is increasingly popular in Malaysia. Many companies, organizations and consumers are starting to be aware that social media influencers will be the new trend of marketing promotional tool to enhance brand awareness and expand the reach of organization through collaboration. Previously, social influencer marketing was not a popular marketing strategy for SMEs and the reach is not so effective but with the emergence of Internet and social media such as Facebook, Instagram and YouTube, influencer marketing became an effective tool in building brand awareness and loyalty. This is due to the border-less structure of the World Wide Web where anyone and everyone can directly interact. It gave an opportunity for common individuals to become influencers as well. This is proven with social networking sites. These sites provide a platform where influencers can easily interact with their followers.

Based on the Statista (2018), the daily time spent by internet users on social networking sites is gradually increasing which is from 90 minutes in 2012 data to 135 minutes per in 2017 data. Thus, people nowadays are beginning to trust what social media influencers say, review and 
comment about the products they used. Kaplan and Haenlein (2012), specify the social media influencer will create and share their content had an essential impact on consumers. There are limited research in the area of social media influencer in the Malaysian context. Most of the previous research did not emphasis on particular target audience and only few studies focused on the impact of social influencer towards male and female students. Therefore, this research will look into how the gender of social media influencer can influence emerging adults. The research also intended to find out which gender more effectively affect university students with different perspectives. The Internet Users Survey (IUS) conducted by the Malaysian Communications and Multimedia Commission (MCMC) in 2016 shows that there are $97.3 \%$ internet users who own a Facebook account, 56.1\% own Instagram account and $45.3 \%$ of internet users own Youtube account in Malaysia. Across leisure activities, entertainment and other functions of Internet, visiting social network sites has $89.3 \%$ (the second highest) apart from texting $(96.3 \%)$.

A report conducted by We Are Social and Hootsuite in 2018 shows that among 7.593 billion population, there are 4.021 billion (53\%) internet users around the world which up 7 percent year-on-year. Among 4.021 billion internet users, 3.916 billion (42\%) are active social media users, up 13 percent year-on-year and 2.958 billion (39\%) are active mobile social users. In addition, a figure of the breakdown of Facebook's global users by age and gender show that there are 610 million of Facebook users who are between 18 to 24 years old which sum up with 250 million female users and 361 million male users. It is the second highest group of users compare to age from 13 to 65 .

According to Director of Content for Olapic, the daily life of consumers nowadays filled with media and visual content. Therefore, they are more aware to identify the sources of information and character that they can trust. Moreover, many blogger and content creator are turning to become social influencers to identify products, services, and travel diary that influence from their own characteristic and lifestyle. However, according to PMYB Influencer Marketing Agency, there are not many studies that relate gender differences with the impact of social influencers. Undeniably, the study had massive potential for future research. Besides that, there are few studies on the differences between the genders while it comes with the differences of their use of social media (Andrew, 2017). Thus, it is not too difficult to find out through the observations as to how men and women may react differently to the social media influencers. People are becoming more trusting of social media influencers due to their trustworthiness and credibility. Izea (2017) results showed that more than $67 \%$ say the credibility of social media influencer is making the post effective in United States who use in media. So, the studies will fill the gap in research that was mostly done in other countries but not in Malaysia.

\section{Research Objectives (RO)}

RO1: To determine the trustworthy of emerging adults towards recommendations made by social media influencer and its effect on their intention to purchase.

RO2: To discover the styles of promotion used by social media influencers as perceived by emerging adults.

\section{Research Questions (RQ)}

RQ1: Do emerging adults trust the recommendations made by social media influencer and its effect on their intention to purchase? 
RQ2: What are the styles of promotion used by social media influencers as perceived by emerging adults?

\section{Significance of Study}

Social media influencers are first explored in the endorsing sector, especially to make buzz among youthful markets and grow web-based social networking scope in organizations. It is important to investigate more about the factors that lead emerging adults to be influenced by male and female social media influencer as social influence marketing is growing rapidly. We intended to identify the purchasing purpose of emerging adults after being influenced by male and female social media influencer. The research will contribute to fill the gap for the current research on social media influencer which mostly done in other countries but not in Malaysia context. The companies might use the findings as a new insight for their marketing purpose.

\section{Literature Review}

\section{Social Media Networks: Instagram \& YouTube}

The advancement of technology has triggered the emergence of new media that is occasionally renowned as the social media networks. Social media networks has become the platform in the Internet that use by every single person that have the access on it. The social media users become the audience that consumes all the information sharing through the sites. McIntyre (2014) state that emergence of new social media sites has eventually replace the traditional media. As such, newspapers have been gradually replace by the news online portals. Public would rather spend their time reading news online than watching news from the television. Moreover, social media allows people to have new place for social networking through online as well as providing a platform for people to outshine each other competitively. Social media has been attracting mass audience due to its variety of websites. People with different preference will allocate themselves to the relevant websites in order to serve their own interest (McIntyre, 2014). The two main platform of social media that have been choose majority by the people is Instagram and YouTube.

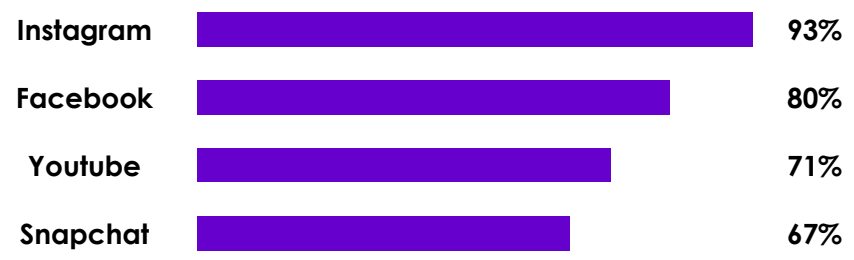

Figure 1.Types of Media Used By Influencers on Daily Basis.

Source: indaHash Labs, Women Are the New Media

Figure 1 explain that the three main media used by influencers on daily basis are Instagram, Facebook and YouTube. Hence, it shows that social media users inclined towards the use of Instagram and YouTube for getting the information, entertainment purposes and many other reasons that applied to the use of it. Instagram is the social media page that focus more on photography because photo is the most engaging type of content. Most of the post include sign \# called hashtags. The sign allow to track the posts and identify or just search for content (Szczurski 2018).

\section{Social Media Influencer}

Influencer can be recognized as an individual that have the ability to influence someone or the audience that might follow him or her through their social media platforms. According to 
Vaibhavi and Leena (2018) on the popular social media platforms, there are many social media users that follow popular social media accounts, hence it can be understood that these new opinion leaders generation has been called as a social media influencers. On the other hand, the characteristics as an influencer also an individual that able to influence others purchase decision as the results of their impact through the information sharing and relationship connection with their followers or audiences. This scenario happens due to the new trends of endorsement by the social media influencers whereby they have been approach by companies or organizations that wanted them to endorse or review their products. Hence, social media influencers then would review and endorse products and services through their personal site, tweets and posts in social media, for example, Instagram, YouTube, Facebook and other social media sites.

Social media and blogging were not initially intended to be a marketing platform, but a place for bloggers to share their opinion on certain topics, provide information that one might needed when come across to their page and for the other entertainment purposes (Vaxjo, 2017). However, the trends have now change where the page that have quite number of followers could eventually give impact to the audiences. The marketers are now switch over to social media influencer as the product and services endorsers because they believe that social media influencers improve the brand sentiment and provide authentic storytelling. As such in photography platforms like Instagram, the fashion influencers mostly endorse a product by wearing it and then tagging the picture with the name of the brand (Izea, 2017; Vaibhavi \& Leena, 2018). It goes the same method with cosmetic or beauty influencer where they would actually try and use the product by themselves when endorsing through their social media accounts. Most probably through YouTube platforms where we can see that there are lot of beauty influencer that will provide "Get Ready With Me", \#GRWM, which is a video that allowed the followers to watch how they use the cosmetics products by sharing information in the same time. Which on a video platform such as YouTube, influencers have the liberty and the time to properly explain the features of a product as well express their opinions of the same (Media Kix, 2016; Vaibhavi \& Leena 2018).

Besides that, being an "influencer" implies a specific way of life, societal position and now a profession. Some of the influencers bring home the bacon out of their internet-based life abilities, some view it as a side employment and energy. They prepare to be proficient, invest hours setting up the best substance and connecting with their audiences. Their companions and other social media users impact them the most (rather than conventional media which has little impact). They expand items they see inside the social media world in which they live (IndaHash, 2017). Glucskman (2017) stated that influencer has become tool for marketing companies and it also become one of the most important business strategies that fully utilizing social media sites. The influencers has been approach by the marketers because they have built good reputation and images towards their audience, hence it become one of the strategy in marketing to endorse their product or services through social media influencers.

\section{Gender and Communication Theory}

This research has been conducted by using gender and communication theory as the framework of the study. Gender differences are additionally present in the manners in which teenagers utilize the internet and social media, despite the fact that utilization designs have moved after some time. It has been said that high school young girls in the U.S were more dynamic bloggers than young boys - maybe the first occasion when that females were more dynamic members than guys in an open public method of PC interceded correspondence. Young boys will probably transfer online recordings and utilize video-sharing applications. 
The theory explain that gender have different styles and ways to communicate towards their audiences. According to Fahad Alzahrani (2016) the popularity of social media has shape the structural backbone of the modern society. Women and men has perform different roles in different interconnected social networks. Current research has reveals the striking differences in behaviour within social networks between men and women. Whereby, female representative tend to respond to offers of friendship from persons of the opposite sex much faster than men. Research reveals men and women tend to use social networking differently. Their difference exists in all area, starting with security and ending with information they share with their friends. It has been seen that on the network level, women tend to be more effective communication partners.

The study is conducted to understand the impact of male and female media influencers towards their followers and audiences. There are differences between male and female ways of communicating towards their respective receiver of the information the so called audiences or followers. This has been supported by Szell and Thurner (2013) where they have studied about the differences that has occur in behaviour of men and women in social networks with the factors that contribute to the occurrences of those differences. The results from their study have shown that females attract more positive behaviour which they said that females tend to be homophily compare to men. Homophily is meant to be the tendency of people to associate and connect with similar others (Szell \& Thurner, 2013). While according to the research done in 2012 by Haferkamp, Eimler, Papadakis and Kruck that explore gender differences in use of social networking and self-presentation from the psychological perspective of gender. The study have stated that women tend to pay their attention on creating a positive image of themselves in social networking as compare to men. Thus, it explain the number of majority female social media influencer currently in the market. It goes along with the research that we are conducting where the approach of females and males while using social media to become an influencer is different from each other.

According to Lakshmi et al (2017) male and female has different attraction towards media content on the Internet. Males prefer straightforward advertisements that allow them to obtain information of the product and made aware of the pros and cons of the product. In addition, Tannen $(1990,1995$ \& 2002) stated that women and men communicate in different genderlects or gender-specific dialects. Women tend to engage in rapport talk or leaning towards relationship-oriented talk, whose primary function is to build understanding and empathy within a wider group of audiences. Opposite of that situation, men is tend to engage in report talk or task-oriented talk, whose primary function is to produce solutions towards problems (Baden Eunson, 2012). Thus, it could be understand that female and male social media influencers have difference way of approaching and communicating to their followers in their social media platforms. As such, through video like using YouTube to endorse new cosmetic products, women influencers tend to establish rapports with their female audiences whose most likely watching the video and in order to successfully convey the message.

\section{Methodology}

A total of 8 participants from 18 to 21 years old were involved in this study. The first group is all male, they must access social media such as Instagram or YouTube more than 10 times and subscribed more than 10 profiles of channels of social influencer in Instagram and YouTube in a month. The second group is all female, they need to do the same things as well. In addition, they also need to use social media at least 5 hours in a day. 


\section{Research Procedure}

Focus group interview method were used as the medium to collect data from participants. The participants were required to answer the questions after viewed the videos and images. Participants will watch four videos (two product reviews and two advertisements) from Youtube and view the work of four influencers from Instagram. The interview session consisted semi-structured questions and it is estimated to take approximately 30 to 45 minutes for participants to complete the interview session.

\section{Research Design}

In this research, the qualitative research method was used to answer the research questions proposed in this research. Besides, the focus group and content analysis are implemented for this study to understand the context such as what are the factors that lead emerging adults to be influenced by male and female social media influencer. Focus-group interview method is a group discussion method to understand the responses from participants based on the questions that the mediator discuss in group. A qualitative research as "an inquiry process of understanding based on distinct and methodological traditions of inquiry that explore a social or a human problem (Srivastava \& Thomson, 2009). Therefore, in this research, qualitative research design is used to understand the factors that influenced by male and female social influencer.

\section{Research Instrument}

A semi structured questionnaires is used to measure the factors that influence social media influence. From YouTube, beauty and technology genres are chosen. Both these genres include viewing the product review first, and then followed by the advertisement. From Instagram, the work of four influencers has been chosen. After viewing the videos, the sample will then be shown images from popular Instagram accounts. These accounts include models, sportspersons and beauty bloggers. These images will be shown to the sample before and an image where they have tagged a particular brand of clothing they are wearing. The researcher has selected these images on the basis of the profile's popularity, their work and the kind of images and brands that the Instagram celebrity is endorsing.

\section{Data Analysis}

In this study, the content analysis method was used as a method to analyse the data collected. The eight steps of content analysis were used and the data collection is categorized into themes that identified through secondary literature. The steps for the content analysis are; 1) identify the question to be asked and constructs to be used, 2) choose the videos to be examined, 3) decide on the size or type of response to be counted in the analysis (unit of analysis), 4) determine the categories into which the responses are to be divided, 5) generate a coding scheme, 6) conduct a sample or pilot study and revise the categories and coding scheme as needed, 7) collect the data, 8) assess validity and reliability (Harris,2001). The validity and reliability of the coding should be checked consistently because human coders usually make mistake during coding process (Datt, 2018). The researcher had use inter-coder reliability check by duplicating their research efforts under different conditions and check the similarities and differences in readings, interpretations, responses to, or uses of given texts or data (Krippendorff ,2004) Triangulation has been used in this process to test the validity of the participant's interviews where the researcher examined the data from different respondents until there is a pattern or contradictions beyond the individual experience. 


\section{Findings and Discussion}

Findings showed that there is a difference in perception of university students towards male and female social media influencers. In general, respondents follow influencers from both genders but there is a difference in the purpose and perception. For male respondents, they follow female influencers that are attractive in order to admire them and male influencers for fashion and those that stream or post videos of them playing video games entertainment. Female respondents, meanwhile, follow female influencers to get information on the latest beauty and fashion trends. In addition, instead of video gamers, female respondents are more likely to follow male influencers who post funny sketches for entertainment.

\section{Trustworthiness and Intention to Purchase}

Both genders are more likely to trust social media influencers who promote certain products on their channel compared to paid advertisements. Respondents viewed recommendations made by social media influencers as more trustworthy since they give both positive and negative comments in their reviews, making them seem unbiased.

"...if you like someone in the social media, if they promote something obviously social media influencer, they don't just err promote the good side of it. They did promote the bad side of it. So, you know that err these product is good or bad."

[Respondent C, female aged 21]

For male respondents, they are more likely to purchase video games recommended by male influencers as these influencers will provide information on the products after testing them out themselves. Female respondents are also more likely to purchase beauty products promoted by female influencers as they trust the information and recommendation given by these influencers.

\section{Style of Promotion}

In general, both genders agree that they are more likely to follow influencers who present their content in creative and informative ways. For male respondents, the first few seconds of the video will influence their decision on whether to keep watching or not. Therefore, videos that are entertaining can grab their attention and information about products being promoted are usually included at the end of the video.

"Erm... I think...err... laptop or smartphone are the products that attracted me because I'm interested on the kinds of things. The social media influencers can present the promotion in a very funny and interested way."

[Respondent B, male aged 20]

For female respondents, while they admit that entertaining videos make them likely to keep watching after the first few seconds, they are more likely to watch towards the end if the video also provides useful information. In other words, male respondents are more inclined to finish watching a video if most of the content is entertaining and information about the product is added at the end. Female respondents will watch the entire video if it is at first entertaining but contains more information throughout the video.

\section{Conclusion}

Social media is an inseparable part of an emerging adult's life. While male and female respondents have preferences towards their own corresponding genders, they are all in 
agreement that content made by these influencers need to be entertaining as well as informative in order to attract their attention. However, it is interesting to note that female respondents prefer more information along with entertainment as opposed to male respondents who prefer more entertainment value than information.

\section{References}

Andrew (2017). Do Men and Women Respond Differently to Influencer Advertising? Psychology in Advertising. Retrieved from: https://pmyb.co.uk/men-women-respondinfluencer-advertising

Datt, S. (2016). 8-step procedure to conduct qualitative content analysis in a research Project Guru. Retrieved from: https://www.projectguru.in/publications/qualitativecontent-analysis-research

Eunson, B. (2005). Communicating in the $21^{\text {st }}$ Century. Australia: John Wiley \& Sons. Retrieved from https://www.academia.edu/6314991/Gender_and_Communication

Gashi, L. (2017). Social Media Influencers- Why We Cannot Ignore Them: An Exploratory Study about How Consumers Perceive the Influence of Social Media Influencers during the Different Stages of the Purchase Decision Process. Bachelor of Science in Business Administration: International Business and Marketing Spring 2017. Retrieved from: https://pdfs.semanticscholar.org/0bcc/3fd002c73e0b818fc98915ce5f63c1b6189f.pdf

Glucksman, M. (2017). The Rise of Social Media Influencer Marketing on Lifestyle Branding: A Case Study of Lucie Fink. Elon Journal of Undergraduate Research in Communications, 8(2).

Harris, H. (2001). Content analysis of secondary data: A study of courage in managerial decision making. Journal of Business Ethics, 34(3-4), 191-208.

Herring, S.C. \& Kapidzic, S. (2015). Teens, Gender, and Self- Presentation in Social Media. International Encyclopedia of Social and Behavioral Science. Retrieved from: http://info.ils.indiana.edu/ herring/teens.gender.pdf

Hussain, I. (2012). Teens, Gender, and Self-Presentation in Social Media. International Educational Technology Conference IETC2012: A Study to Evaluate the Social Media Trends among University Students. 639-645.

Idemudia, E., Achebo, N., \& Adeola O. (2017). The Effect of Gender on Social Media Adoption the Effects of Gender on the Adoption of Social Media: An Empirical Investigation Investigation. Conference: Twenty-third Americas Conference on InformationSystems,Boston, 2017. Retrieved from:

https://www.researchgate.net/publication/319130496_The_Effects_of_Gender_On_S ocial_Media_Adoption_The_Effects_of_Gender_On_The_Adoption_of_Social_Medi a_An_Empirical_Investigation

Influencer marketing: what is influencer marketing? (2012). Retrieved from: http://www.marketing-schools.org/typesof-marketing/influencer-marketing.html

Karima M. (2012). How Men and Women Differ: Gender Differences in Communication Styles, Influence Tactics, and Leadership Styles. 2-32

Karen M. (2014). The Evolution of Social Media from 1969 to 2013: A Change in Competition and a Trend toward Complementary, Niche Sites: The Journal of Social Media in Society. 3(2): 5-25.

Kaplan, A., \& Haenlein, M. (2012). Social media: back to the roots and back to the future. Journal of Systems and Information Technology, 14(2), 101-104. doi: $10.1108 / 13287261211232126$

Krippendorff, K. (2004). Reliability in content analysis. Human communication research, 30(3), 411-433. 
Lakshimi, V. V., Niharika D. A. \& Lahari. G (2017). Impact of Gender on Consumer Purchasing Behaviour. IOSR Journal of Business and Management. 19(8): 33-36. Retrieved from http://iosrjournals.org/iosr-jbm/papers/Vol19-issue8/Version5/E1908053336.pdf

Lim, X. J., M. Radzol A.R., Cheah J. H., \& Wong M. W. (2017). The Impact of Social Media Influencers on Purchase Intention and the Mediation Effect of Customer Attitude. Asian Journal of Business Research. 7(2). Retrieved from: https://www.researchgate.net/publication/321832168_The_Impact_of_Social_Media_ Influencers_on_Purchase_Intention_and_the_Mediation_Effect_of_Customer_Attitud e

Riga (2016). New Trends in Social Media. Latvia. The NATO StratCom Centre of Excellence. Retrieved from https://www.stratcomcoe.org/new-trends-social-media

Statista (2017). Daily time spent on social networking by internet users worldwide from 2012 to 2017 (in minutes). Statista. Retrieved from: https://www.statista.com/statistics/433871/daily-social-media-usage-worldwide/

Soltysinska, B. (2017). Women are the new media: How influencers became publishers. indaHash Labs. Retrieved from: https://labs.indahash.com/wpcontent/uploads/2017/06/indaHash_LABS_report_2017.pdf

Szczurski, M. M. (2017). Social media influencer- A Lifestyle or a profession of the XXIst century? International Journal of Management and Applied Science (IJMAS), 3(10), 47.

Vaibhavi, N. \& Leena P. (2018). Impact of Influencers from Instagram and YouTube on their follower. International Journal of Multidisciplinary Research and Modern Education (IJRME), 4(1), 61-65.

Vaxjo, K. (2017). Choosing the Right Social Media Influencer: A Quasi-Experiment to Explore the Impact of Influencers' Different Characteristics, 5-6. Retrieved from: https://www.diva-portal.org/smash/get/diva2:1107811/FULLTEXT0 